\title{
Attitudes towards varied inclusive language use in Spanish on Twitter
}

\author{
Katie Slemp ${ }^{1}$ \\ York University, Toronto, Canada
}

\begin{abstract}
Research into gender-inclusive language in Spanish has demonstrated that inclusive language generally appears in four forms: doublets, -@, - $x$, and - $e$. There is little research on language attitudes towards the use of gender-inclusive language in Spanish, although studies exist for other languages. The present study compiled a corpus of published tweets that contained the markers -@, - $x$, and - $e$. Based on this data, hypothetical tweets were constructed that fell into four different categories, corresponding to the author of the tweet: business, personal, academic, and political. These hypothetical tweets were built into an attitudes survey that was distributed on Twitter. Findings indicate that language attitudes for each type of inclusive marker and category of tweet are generally positive. Statistical analysis indicates a significant relationship between gender identity and attitudes towards the use of inclusive language in the political category.
\end{abstract}

Keywords: language and gender; gender-inclusive language; language reform; language attitudes

\section{Introduction}

Spanish, like other major Romance languages, has binary grammatical gender. This means that every noun (and modifier), animate or not, is marked with either feminine or masculine gender. Inanimate nouns like floor (el piso) and table (la mesa) are masculine and feminine, respectively. Animate nouns are also marked for gender, and this generally corresponds to the apparent biological sex of the referent. As a general rule, nouns that end in - $o$ are masculine, and those that end in - $a$ are feminine (although there are exceptions). This has become a source of discontent among Spanish speakers in light of expanding social gender roles and gender identities outside of the traditional binary. Gender ambiguous individuals are unable to express themselves easily in Spanish due to the binary grammatical gender that is required. Furthermore, the Spanish language is dominated by masculine generics, where mixed groups of individuals are referred to in the masculine form. This has been criticized for its erasure of women, and more recently for its erasure of gender diverse individuals.

The criticism of the widespread use of masculine generics began predominantly in the 1980s. Due to feminist movements, many language academies published guidelines on how to incorporate gender-inclusive language that included both men and women in Spanish. At that time, the strategy was primarily to incorporate the use of doublets in the language. With the widespread use of the personal computer came a further innovation, the inclusive marker - @, which indicates

${ }^{1}$ Corresponding author: kslemp@yorku.ca 


\section{ATTITUDES TOWARDS VARIED INCLUSIVE LANGUAGE USE IN SPANISH}

both masculine and feminine gender simultaneously (with an $a$ surrounded by an $o$ ), thus facilitating writing, although it is generally pronounced orally as a masculine generic. To express gender identity outside of the traditional male-female dichotomy, Spanish speakers have begun to innovate with their language, despite normative pushback. The first innovation to appear that circumvented the gender binary in Spanish was in 2004, when the $-x$ was incorporated. The $-x$ has received criticism for not following phonological and syllable structure in Spanish, for being a borrowing from English, and, by language purists, for being an attempt to dismantle the heritage of the Spanish language. Although it began as simply a way to eliminate gender from the Spanish language (similar to the incorporation of the $x$ in womxn), because it has been criticized in the ways stated previously, the $-x$, as well as doublets and -@ are in use today. The newest innovation to appear, in the mid 2010s, is the gender-inclusive morpheme - $e$. The incorporation of this morpheme has increased dramatically. Phonologically, there is no debate as to its pronunciation. Furthermore, it mimics existing nouns and adjectives in Spanish (e.g., estudiante 'student', verde 'green') that are not overtly marked for gender.

The majority of these innovations do not follow guidelines set by language institutions in Spanish. For this reason, it is important to examine how Spanish users themselves are incorporating inclusive language. One way to do this is by utilizing Twitter, a social media site where users post thoughts, questions, and opinions in less than 280 characters. Twitter is a useful resource because it is public and informal. Furthermore, there has been no research that has analyzed attitudes towards the use of gender-inclusive language in Spanish and whether these attitudes differ according to the person who is using innovations. Finally, we do not know if there are any relationships between the demographic characteristics of individuals and the attitudes they have towards inclusive language. For this reason, the research questions guiding this investigation are:

1. How are users on Twitter incorporating Spanish gender-inclusive language?

2. What are the language attitudes towards the use of gender-inclusive language on Twitter? Do these attitudes change depending on the perceived author of the tweet?

3. Are there any relationships between demographic variables and language attitudes towards gender-inclusive language?

\section{Literature review}

\subsection{Gender in Romance}

All major modern Romance languages, apart from Romanian, ${ }^{2}$ have a binary grammatical gender system (Loporcaro, 2018). The masculine form in Romance is the syntactically unmarked form (in the case of Spanish, nouns and their agreements generally ending in -o) and systematically occurs on agreement targets in default contexts. Noun morphology aids in gender agreement and is a reliable cue for establishing correct agreements in the phrase and sentence as a whole (Alarcón, 2011). Native Spanish speakers use overt morphology as a strong linguistic cue for gender agreement in both comprehension and production (Alarcón, 2011).

\subsubsection{Inclusive language in Spanish}

Inclusive language generally only aims to modify animate nouns with human referents, or rather, it affects semantic gender rather than grammatical gender. Semantic gender is determined by the apparent biological sex of the referent and social gender roles. In Spanish, both grammatical

\footnotetext{
${ }^{2}$ Romanian has a grammatical gender system, but retains a neuter gender as well as masculine and feminine gender.
} 


\section{KATIE SLEMP}

and semantic gender are generally denoted by either an - $o$ (masculine) or an - $a$ (feminine). Spanish nouns with grammatical gender like floor (el piso) and table (la mesa) would not be altered by inclusive language, but nouns with semantic gender (e.g., chico and chica, 'boy' and 'girl'), would.

There are different types of inclusive language currently found in the Spanish language. In keeping with the growing feminist movement in Spain in the mid 1980s, concerns were raised as to the interpretation of generic words and expressions, and consequently, the first guidelines for non-sexist language in Spanish were published (Ministerio de Educación y Ciencia, 1988). This document offers various solutions, mainly encouraging doublets or collective forms. Doublets tend to be unwieldy in writing, and therefore a new innovative marker appeared that was compact, yet unpronounceable, the -@.

In recent decades, one way to represent gender-inclusive language has been the symbol @ which denotes both masculine and feminine endings ( $-o$ and $-a$ ), or rather male and female variations of animate nouns with human referents. For example, a student body could be referred to as $l @ s$ alumn@s ('the students' MASC/FEM.PL), which would normally be pronounced with a doublet los alumnos y las alumnas ('the students MASC.PL and the students FEM.PL'), but could also be pronounced as los alumnos ('the male/mixed students' MASC.PL) because the @ symbol does not have an easily defined sound. This supposed solution was designed to combat the prescriptively accepted masculine plural form which is traditionally viewed as generic (Real Academia Española, 2018). For example, addressing a student body as los alumnos would include both males and females. In recent years, - @ and doublets have been criticized as not being inclusive of all genders, as they still indicate a binary male/female option (de Onís, 2017). Furthermore, according to Guidotti-Hernandez (2017), the - @ was intended to be unpronounceable. Guidelines for non-sexist language have appeared recently in Latin America (Ramírez Vélez, 2009) and, in these guidelines, the author recommends avoiding using the - @ because it is not a "linguistic symbol" but recommends using doublets instead (Ramírez Vélez, 2009, p. 19).

Due to criticism of the binary nature of the suffix - @ and of doublets, a new way to mark inclusivity appeared. The grapheme $-x$ has begun to be incorporated since the early 2000 s as an ungendered suffix. It first appeared in 2004, in written discourse as a non-gendered alternative, meaning that the $-x$ effectively crosses out or eliminates a gendered denotation (Milian, 2017). This option has been popularized by the term Latinx, referring to Latin American people of all genders. According to Milian (2017), the term Latinx has been traced to online forums in the 1990s, but the first major appearance of latinx was in the 2004 (Fall) volume of the journal Feministas Unidas (Padilla, 2016). Some argue in favor of the $-x$ because of its simplicity. For example, latinx is easier to type than latin@ and latina/o from a mobile device (DeGuzmán, 2017). While the usage of this grapheme has been further and further incorporated into written discourse (one can easily find occurrences of todxs, lxs chicxs, etc.), the pronunciation of this $-x$ has yet to be studied in detail, although some studies exist (e.g., Milian, 2017; Slemp et al., 2019; Slemp, 2020). VidalOrtiz and Martínez (2018) state that latinx, if accepted, is an "explicit incorporation" (p. 394) of gender minorities.

The term latinx is used most frequently by students in college and universities (Salinas \& Lozano, 2017). Latinx began spreading beyond LGBTQ+ communities in 2015, out of a desire to get away from the masculine-centric latino and the binary gender-inclusivelatin@ (Scharrón-Del Río \& Aja, 2020). The introduction of Latinx was driven by millennials on social media, like Facebook and Instagram, and not in spaces related to the academy, apart from the initial 


\section{ATTITUDES TOWARDS VARIED INCLUSIVE LANGUAGE USE IN SPANISH}

appearance in 2004 (Vidal-Ortíz \& Martínez, 2018). It is not until 2016 that we see Latinx reappear frequently in conference and association presentations (Salinas \& Lozano, 2017). Millennials use the $-x$ to express their dissatisfaction with gender binaries while seeking gender visibility, or perhaps invisibility (Guidotti-Hernandez, 2017). Latinx moves beyond latin@ to encompass genders outside of the limiting man-woman binary, despite the previous movement regarding - @ as inclusive (Guidotti-Hernandez, 2017). Many researchers state that the use of latinx aims to neutralize the sex-gender binary inherent in the Spanish language (e.g., Arce, 2015; HaddockLazala, 2016). DeGuzmán (2017) writes that the use of the $-x$ may not be the ultimate solution to gender inequality in the Spanish language, but rather a critique of gender centrality in genderneutrality or fluidity.

The $-x$ has been critiqued for being problematic in terms of pronunciation, and a new inclusive morpheme has appeared in response: $-e$. To clarify, the incorporation of the grapheme $e$ as a not overtly marked gender suffix to avoid the overt gender markings $-o$ and $-a$ is an innovation that mimics existing nouns and adjectives in Spanish (e.g., estudiante 'student', inteligente 'smart'). Nouns and adjectives that are normally overtly marked are modified by the incorporation of $-e$ (amigo MASC.SG becomes amigue NEUT.SG, pequeño MASC.SG becomes pequeñe NEUT.SG). Vidal-Ortiz and Martínez (2018) affirm that the closest linguistic element to a gender-neutral suffix is the $-e$ and it has been used for years by activists in Latin America. The authors also state that the $-x$ is often pronounced as /e/ to avoid the consonant cluster $/ \mathrm{ks} / \mathrm{which}$ is unpronounceable in Spanish as a syllable nucleus (Vidal-Ortiz \& Martínez, 2018). This is affirmed by Slemp et al. (2019), where the phrase carrera para todxs is pronounced as [to.ðos] but corrected to [to.ðes]. Zentella (2017) notes that a term like latine has been used to circumvent the binary gender of latino, latina/o, and latin@.

In the YouTube corpus compiled by Slemp et al. (2019), the researchers find that the countries where inclusive language occurs the most are Spain and Argentina. Additionally, the written $-x$ forms appearing in the titles of the videos are primarily pronounced as doublets (either masculine-feminine order or secondarily as feminine-masculine order). For example, a video with the word todxs would begin with a spoken greeting to todos $y$ todas, not *[to.dk.ses] or [to.ðe.ki.ses]. The second most common way that written $-x$ forms were pronounced was using /e/. Forms using $-e$ in writing or /e/ in pronunciation began to appear in 2013 in the YouTube corpus used by Slemp et al (2019). This corpus is the only one which provides a relative chronology of different inclusive language forms. Through a survey and interviews, Slemp (2020) finds that the most common way to express inclusivity in speech and writing is the inclusive marker $-e$. Additionally, the statistically significant variables in the study are birth country and gender identity. The most common reported birth countries of users of inclusive language are Argentina, Colombia, and Spain.

\subsection{Language variation and change}

Normally, changes in the written structure of a language follow changes in spoken language (Fought, 2013); gender-inclusive innovations in this case are the opposite, where the - @ and $-x$ markers have been introduced into written language without regard for normative pronunciation, and without even considering whether they will be possible to pronounce at all. Adolescents are frequently the sector of speakers that drive language variation and change (Kirkham \& Moore, 2013). They are between adulthood and childhood, which creates the perfect environment to "adapt, resignify and reconstrue language variation" (Kirkham and Moore, 2013, p. 399) so it is not surprising that the main generation participating in the Latinx movement is the 


\section{KATIE SLEMP}

adolescent group and younger adults (e.g., Guidotti-Hernandez, 2017; Slemp et al., 2019; Slemp 2020). Additionally, women are more likely to use innovative forms in language when prestige is not a consideration (Queen, 2013). Ethnicity may also contribute to the pronunciation of genderinclusive language (Fought, 2013), and though it is not the focus of this project, one cannot ignore the intersectional relationship that exists between gender and ethnicity (Eckert \& McConnell-Ginet, 2003).

Language purists steadfastly oppose the inclusion of the $-x$ and say that it could be the death of the Spanish language (Milian, 2017). In actuality, the ability of a language to change and adapt is a sign of plasticity and health because thriving languages undergo constant changes while remaining recognizable as the same linguistic system (Vidal-Ortiz \& Martínez, 2018). PrewittFreilino et al. (2012), Eckert and McConnell-Ginet (2003), and Ehrlich and King (1992) remind readers that linguistic modification must be accompanied by social and political adjustments in order to truly change existing asymmetries in gender. Sarlo and Kalinowski (2019) also state that social change needs to accompany the changes happening in Spanish to allow for inclusive language. Indeed, Ehrlich and King claim that language is not a "neutral vehicle" and because it also conveys social values, therefore the introduction of gender-neutral or inclusive terms does not mean that language will be nonsexist (1992, p. 152).

\subsection{Language attitudes}

According to Fishbein and Ajzen (2011), people use gender-inclusive language when they (a) hold favorable attitudes toward the behavior, (b) perceive supportive norms, and (c) perceive ease in utilizing inclusive language. Sczesny et al. (2015) completed two studies with German native speakers where participants reported moderately positive attitudes towards the use of gender-inclusive language but only incorporated gender-inclusive language forms in about four out of ten of the fill-in-the-blank responses. Additionally, gender-inclusive language was significantly predicted by frequency of past behavior and marginally by intentions. Sczensy et al. (2015) found that gender-inclusive language is a product of both deliberate and habitual factors. Spontaneous use of inclusive language was found to be guided by explicit intentions to use it as well as more implicit processes involving use of it in the past (Sczesny et al., 2015).

One major factor that makes individuals use or reject gender-inclusive language is the novelty of gender-fair forms, which conflicts with speakers' linguistic habits (Blaubergs, 1980). Additionally, initiatives for gender-inclusive language were first instigated by activist movements and for that reason are often met with negative reactions (Sczesny et al., 2016). In general, the reaction to gender-inclusive language depends on attitudes toward gender arrangements (Jost \& Kay, 2005; Carney et al., 2008). In Sczesny et al. (2015), sexist speakers avoid inclusive language because they are reluctant to change their linguistic habits and they also deliberately use a form of language that treats males as the norm and makes women less visible. According to Sczesny et al. (2015), "interpersonal communication contributes to gender stereotyping via written words, spoken utterances, and the mass media" (p. 943). Language not only allows us to transfer information, but also to express social hierarchies, including gender.

Research has linked gender-exclusive language with sexist beliefs and attitudes (Swim et al., 2004; Sczesny et al., 2015). This can go as far as those with sexist beliefs making deliberate decisions to use language that perpetuates gender stereotyping and supports patriarchy, as seen in Sczesny et al. (2015) where participants deliberately avoided using gender-inclusive language because they viewed it as oppressive political correctness or felt that it was unnecessary due to the availability of (false) masculine generic. Gender belief systems can lead to people adopting certain 


\section{ATTITUDES TOWARDS VARIED INCLUSIVE LANGUAGE USE IN SPANISH}

language forms. For example, Jacobson and Insko (1985) show that participants with stronger sexist attitudes choose non-sexist pronouns in English (e.g., they) less frequently than participants with less sexist attitudes. Men score higher on sexist attitudes, and men have been found to use more masculine generic pronouns than women (e.g., Rubin et al., 1994; Pauwels, 2003; Cralley \& Ruscher, 2005). These researchers find that non-sexist men used gender-inclusive language primarily when they were not cognitively busy with another task, such as sending an email. Thus, such language use appeared to require explicit, intentional decision making. Studies are being done on why speakers choose to incorporate gender inclusivity into their speech, but not extensively in Spanish (e.g., Sczesny et al., 2015; Patterson, 2017). Sexist attitudes are negatively related to language attitudes towards gender-inclusive language in English (Sarrasin et al., 2012).

Masculine generics can also pose legal challenges for women and other gender minorities, unless it is specified that laws or legal documents apply to all people, or only men (Prewitt-Freilino et al., 2012). In a study by Stout and Dasgupta (2011), women experienced a lower sense of belonging, less motivation, and less expected identification than women exposed to genderinclusive or gender-neutral language, meaning that inclusive language is important to include and motivate women. Gendered language contributes to gender biases by making gender salient to the speakers of that language (Bigler \& Leaper, 2015).

\section{Methodology}

\subsection{Experiment 1}

\subsubsection{Participants (for experiment 1)}

The participants for this study are native or near-native Spanish users, over the age of 18, and have normal or corrected to normal vision.

\subsubsection{Procedure (for experiment 1)}

Using searches for common inclusive terms like todxs/todes/tod@s and amigxs/amigues/amig@s (from Slemp et al., 2019), a corpus was compiled of recent uses of common gender-inclusive terms in Spanish on Twitter. The tweets were collected in November 2020. These markers are also being incorporated in Portuguese to indicate gender inclusivity, but only tweets in Spanish were considered in the present study. The tweets in the corpus were used to create hypothetical tweets from hypothetical authors in four different categories: personal, business, political, and academic. Each category contains three different tweets that incorporate the three inclusive markers used in social media. These tweets were created using an online tweet generator, ${ }^{3}$ so that they would appear like screenshots of actual tweets, and were utilized as part of a language attitudes survey that was created on Qualtrics. The date, time, and number of likes and retweets was kept consistent. Each tweet was accompanied by an acceptability score slider and two follow-up questions: 1 . Why did you choose this score? and 2 . What is the author of the tweet like? The acceptability score was mandatory to complete, but the follow-up questions were not.

The responses were downloaded into an Excel spreadsheet where responses that did not complete at least one acceptability score were deleted $(n=9)$. The remaining participants' data $(n=20)$ were translated into English and input into jamovi (The jamovi project, 2019) where statistical analysis was completed.

\footnotetext{
${ }^{3}$ https://zeoob.com/generate-twitter-tweet/
} 


\section{KATIE SLEMP}

\subsubsection{Stimuli (used in procedure for experiment 1)}

An example of the hypothetical tweets created for the present study is shown in Figure 1, below.

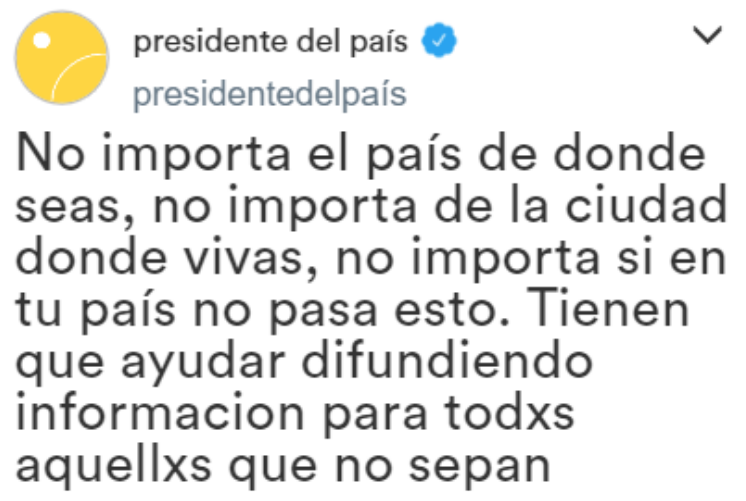

4:17 PM. Aug 14, 2019 .Twitter for Adroid

15 Retweets 100 Likes

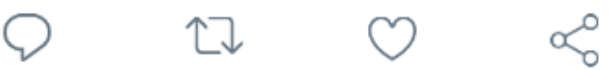

Figure 1. Hypothetical tweet from the author 'country president'. Translation: It does not matter the country you come from, it does not matter the city you live in, it does not matter if in your country this does not happen. You all have to help distribute this information for all NEUT.PL of them NEUT.PL that do not know.

\section{Results}

The following section presents the data collected from the Twitter corpus and the language attitudes survey. There was a total of 20 participants in the survey data, and the demographic variables are presented in section 4.1. The quantitative data for the Twitter corpus and the survey are presented in section 4.2. Finally, section 4.3 contains the qualitative responses from the survey.

\subsection{Demographic variables}

\subsubsection{Gender identity}

Table 1. Frequencies of reported gender identity.

\begin{tabular}{lcc}
\hline Gender identity & Count & $\%$ of total \\
\hline Woman & 13 & $65 \%$ \\
Man & 5 & $25 \%$ \\
Gender diverse & 2 & $10 \%$ \\
\hline
\end{tabular}

Participants identifying as women comprise the majority of the sample, while men make up only a quarter, and only two individuals (10\%) selected a gender identity that was not man or 


\section{ATTITUDES TOWARDS VARIED INCLUSIVE LANGUAGE USE IN SPANISH}

woman. These two individuals had to be combined into one category, although they did not select the same gender identity, for statistical analysis.

\subsubsection{Other demographic variables}

The other demographic variables were found to have no statistical significance and will therefore not be discussed in the present article.

\subsection{Quantitative results}

\subsubsection{Twitter corpus}

The Twitter data was collected on various days throughout November 2020, utilizing the same search terms each time and collecting the tweets starting at the top of the list. The most popular inclusive marker was $-e$, followed by $-x$. The breakdown of the Twitter data mine is found below in Table 2 .

Table 2. Inclusive markers on Twitter.

\begin{tabular}{lcc}
\hline Inclusive marker & Counts & $\%$ of total \\
\hline$-x$ & 13 & $33 \%$ \\
$-e$ & 18 & $45 \%$ \\
$-@$ & 9 & $22 \%$ \\
\hline
\end{tabular}

\subsubsection{Acceptability scores of inclusive markers and categories}

Below, the group means for the type of inclusive marker and tweet category are presented. The newest inclusive marker, $-e$, has the highest average acceptability score, and the $-x$ has the lowest.

Table 3. Average acceptability score for each inclusive marker.

\begin{tabular}{lc}
\hline Inclusive marker & Average acceptability score \\
\hline$-x$ & 3.42 \\
$-e$ & 3.62 \\
$-@$ & 3.49 \\
\hline
\end{tabular}

The tweet category with the highest average acceptability is the academic tweets. The lowest means are from the personal and business categories (see Table 4, below).

Table 4. Average acceptability score for each tweet category.

\begin{tabular}{lc}
\hline Tweet category & Average acceptability score \\
\hline Academic & 3.87 \\
Personal & 3.33 \\
Business & 3.33 \\
Political & 3.51 \\
\hline
\end{tabular}




\section{KATIE SLEMP}

There is no significant difference between the group means of the types of inclusive marker or tweet categories via One-Way ANOVA.

\subsubsection{Significant results}

After completing statistical analysis, the only demographic variable found to have statistical significance on the data via a One-Way ANOVA was gender identity. The mean, standard deviation, and standard error for each gender identity can be found below in Table 5 .

Table 5. Descriptive statistics by gender identity (collapsed).

\begin{tabular}{|c|c|c|c|c|c|}
\hline & Gender & $\mathrm{N}$ & Mean & SD & SE \\
\hline \multirow[t]{3}{*}{ Political } & Diverse & 2 & 2.83 & 0.236 & 0.167 \\
\hline & Man & 5 & 2.60 & 2.278 & 1.019 \\
\hline & Woman & 11 & 4.20 & 0.748 & 0.226 \\
\hline \multirow[t]{3}{*}{ Personal } & Diverse & 2 & 4.17 & 0.236 & 0.167 \\
\hline & Man & 5 & 2.07 & 1.673 & 0.748 \\
\hline & Woman & 9 & 4.07 & 1.103 & 0.368 \\
\hline \multirow[t]{3}{*}{ Academic } & Diverse & 2 & 4.67 & 0.471 & 0.333 \\
\hline & Man & 3 & 3.11 & 2.411 & 1.392 \\
\hline & Woman & 8 & 3.96 & 0.744 & 0.263 \\
\hline \multirow[t]{3}{*}{ Business } & Diverse & 2 & 4.17 & 0.707 & 0.500 \\
\hline & Man & 5 & 2.07 & 1.770 & 0.792 \\
\hline & Woman & 9 & 3.78 & 1.067 & 0.356 \\
\hline \multirow[t]{3}{*}{$-x$} & Diverse & 2 & 3.63 & 0.177 & 0.125 \\
\hline & Man & 4 & 2.25 & 2.072 & 1.036 \\
\hline & Woman & 12 & 3.65 & 1.184 & 0.342 \\
\hline \multirow[t]{3}{*}{-@ } & Diverse & 2 & 3.88 & 1.237 & 0.875 \\
\hline & Man & 5 & 2.15 & 1.867 & 0.835 \\
\hline & Woman & 8 & 4.07 & 1.268 & 0.448 \\
\hline \multirow[t]{3}{*}{$-e$} & Diverse & 2 & 3.63 & 0.884 & 0.625 \\
\hline & Man & 5 & 2.15 & 2.118 & 0.947 \\
\hline & Woman & 9 & 4.28 & 0.678 & 0.226 \\
\hline
\end{tabular}

Table 5 (above) displays the group averages for each tweet category and inclusive marker. Women rated the political tweets more highly than the gender diverse individuals and the men, who had the lowest group mean. The men also had the highest standard deviation, showing there is a lot of variation in the group. In general, the participants that identified as women consistently rated the tweets positively as there was never a group mean of less than 2.5 . In contrast, the group 


\section{ATTITUDES TOWARDS VARIED INCLUSIVE LANGUAGE USE IN SPANISH}

mean for the participants that identified as men can be seen to be negative in multiple categories above. The two individuals who identified outside of the man-woman binary frequently rated the tweets similarly to the women, although there are a few exceptions: namely, the significant result of the political average. The category found to have a significant relationship with gender identity is political average, shown below in Table 6 .

Table 6. One-Way ANOVA (Welch's) for gender identity.

\begin{tabular}{lcccc}
\hline & $\mathrm{F}$ & df1 & df2 & $p$ value \\
\hline Political & 10.919 & 2 & 6.40 & 0.009 \\
Personal & 3.442 & 2 & 7.42 & 0.088 \\
Academic & 1.396 & 2 & 2.99 & 0.373 \\
Business & 1.775 & 2 & 3.75 & 0.287 \\
$-x$ & 0.793 & 2 & 6.46 & 0.492 \\
$-@$ & 1.713 & 2 & 3.05 & 0.317 \\
$-e$ & 2.164 & 2 & 2.61 & 0.279 \\
\hline
\end{tabular}

The only category that has a $p$-value less than 0.05 is the political average according to gender, although the personal average according to gender has a $p$-value that is near significant. For the personal tweets, the gender diverse individuals and women have means that are high in value and similar in value. The men, however, have the lowest mean and the highest standard deviation again.

\subsection{Qualitative results}

Some of the participants rated the hypothetical tweets according to the grammatical structures and provided this as the reason for their score. On average 1-2 people per tweet provide a grammatical error as the reason for choosing their specific acceptability score (e.g., falta una tilde 'it lacks an accent'; faltas de ortografía 'errors in orthography'). However, some individuals did provide reasons related to their preferences or aversions to the inclusive marker appearing in the tweets. About the $-x$, many participants stated la $x$ es dificil de pronunciar ('the $\mathrm{x}$ is difficult to pronounce'). Similarly, for the - @, many participants state it is difficult to pronounce and additionally@solo podría indicardos géneros ('@ only indicates two genders’). The -e marker seems to be the most positively reviewed, with phrases like buen uso del lenguaje inclusivo ('good use of inclusive language').

Finally, there was one participant (a man, 27-40 years old) who expressed extreme aversions to inclusive language that provided reasons such as:

(1) parece escrito por alguien con retraso mental leve a moderado ('it seems written by someone with mild to moderate mental retardation')

(2) inaceptable por parte de una Universidad que se digne de serlo ceder ante la presión de la agenda política de la izquierda moderna. Una deshonra ('unacceptable for a university that deigns itself to be one, yielding to the pressure of the political agenda of the modern left. A disgrace'), 


\section{KATIE SLEMP}

(3) el uso del morfema 'x' como supuesta marca inclusiva es ajeno a la morfología del español, además de innecesario, puesto que el masculino plural sirve para referirse a colectivos

mixtos

('the use of the morpheme ' $x$ ' as a supposed inclusive marker is foreign to the morphology of Spanish, in addition unnecessary, because the masculine plural is used to refer to mixed collectives').

When ranking the uses of inclusive language, doublets are the most preferred option, and the $-e$ is the next most preferred. When asked why individuals incorporate inclusive language, nine out of ten participants stated something along the lines of visibility, respect, or inclusion. The remaining participant stated porque son ignorantes de las características más elementales del idioma español ('because they are ignorant of the elemental characteristics of the Spanish language'). This is the same participant from the preceding paragraph.

\section{Discussion and conclusions}

On Twitter, the most popular inclusive marker is - $e$. However, inclusive markers are not fully incorporated by users. This can be shown in some tweets where an inclusive marker is used in a common term but not extended to the full morphosyntax and the masculine generic may also appear (por qué andan todxs tan neuróticos 'why are you all NEUT.PL going around so neurotic MASC.PL' tweet from@jorcas00). Additionally, some users use multiple inclusive markers in the same tweet (Amigues, estoy en búsqueda de un depto de 2 ambientes para mí y mis 3 hijxs 'friends NEUT.PL I am looking for an apartment with 2 rooms for me and my three children NEUT.PL' tweet from @meli_nita_). A question for further investigation is: are the $-x$ and the $-e$ (as both genderless markers) equivalent? Above, the $-x$ and the $-e$ are used in the same tweet, but in different words. Does the author view those as the same type of inclusivity?

Overall, participants rated each type of inclusive marker positively (above a midpoint of 2.5 ), with the $-e$ having the highest average acceptability score. By measure of a One-Way ANOVA, there was no significant difference between the group means for the type of inclusive marker. It is not surprising that the $-e$ has the highest rating for acceptability due to its popularity and feasibility of use as seen in the previous literature (Slemp et al., 2019; Slemp, 2020). Similarly, all the tweet categories were also rated positively (above 2.5 average), with the academic tweets having the highest group mean. However, again with the One-Way ANOVA, there is no significant difference between the group means for tweet category.

The only statistically significant relationship found was between gender identity (collapsed) and the political average. Women had an extremely high average for the political tweets (over 4) whereas men had the lowest average for these tweets (only slightly positive at 2.60) and they also had the highest standard deviation. This confirms what the literature review states about women using non-standard forms when prestige is not a factor (Queen, 2013). Twitter is an informal environment, so it could be argued that prestige is not considered a factor. Additionally, the literature shows that women are more supportive of inclusive language (Sczesny et al., 2015).

Many participants reported pronunciation difficulties for the $-x$ and - @ inclusive markers. In regard to - @, many participants also stated that it is problematic because it is binary and only refers to men and women, excluding other gender identities that exist in the world (las y los es que llevaba varios siglos usándose, pero las personas poco a poco vamos entendiendo que existe un grupo que no se identifica con ninguno de las dos. El de las les es más intuitivo para pronunciar 'las FEM.PL and los MASC.PL is what has been used for centuries, but people have been, little by 


\section{ATTITUDES TOWARDS VARIED INCLUSIVE LANGUAGE USE IN SPANISH}

little, understanding that a group exists that does not identify with either of the two. The les NEUT.PL is more intuitive to pronounce').

There was one participant who consistently opposed the inclusion of inclusive language and stated that the masculine pronoun is sufficient to mixed collectives. This individual (man, 2740 years old) used offensive judgements about inclusive language targeting the hypothetical author's intelligence or their supposed political affiliation (18-24 años, Argentina, mujer heterosexual, estudiante universitaria, marxista feminista '18-24 years old, Argentina, heterosexual woman, university student, Marxist feminist'). While this participant provided responses that are sexist and in line with previous research for those opposed to inclusive language (e.g., Sczesny et al., 2015; Sczesny et al., 2016), he did also frequently state that he believed the hypothetical tweet was written by someone from Argentina. This also supports previous research that inclusive language is commonly tied to Argentina (Slemp et al., 2019; Slemp, 2020).

Overall, language attitudes towards inclusive language are positive in relation to hypothetical tweets for each of the inclusive markers and the tweet categories tested in this study. However, the sample in this study is small and language attitudes toward gender-inclusive language warrant more investigation. For example, Twitter is a relatively informal space for communication, so language attitudes might be more positive towards tweets than towards textbooks or official documents and guidelines. Nevertheless, gender-inclusive language is growing in popularity. All of these inclusive markers are present on social media, and every participant in the survey recognized the markers as inclusive, whether they felt inclusive language was necessary or not.

\section{Acknowledgements}

I would like to thank Dr. Michol Hoffman for her assistance in the creation in the survey instrument. Additionally, I would like to thank Dr. Ruth King for feedback on the editing of this paper.

\section{References}

Alarcón, I. (2011). Spanish gender agreement under complete and incomplete acquisition: Early and late bilinguals' linguistic behavior within the noun phrase. Bilingualism: Language and Cognition 14(3), 332-350. https://doi.org/10.1017/S1366728910000222

Arce, W. M. (2015). Reel negotiations: Exploring the relationship between film, religion, and sexuality in the Latino community (Publication No. 10115574) [Doctoral dissertation, Graduate Theological Union]. ProQuest Dissertations Publishing.

Bigler, R.S. \& Leaper, C. (2015). Gendered language: Psychological principles, evolving practices, and inclusive policies. Policy Insights from the Behavioral and Brain Sciences 2(1), 187194. https://doi.org/10.1177/2372732215600452

Blaubergs, M. S. (1980). An analysis of classic arguments against changing sexist language. Women's Studies International Quarterly 3(2-3), 135-147. https://doi.org/10.1016/S01480685(80)92071-0

Carney, D. R., Jost, J. T., Samuel, D., Gosling, S. D., \& Potter, J. (2008). The secret lives of liberals and conservatives: personality profiles, interaction styles, and the things they leave behind. Political Psychology 29(6), 807-840. https://doi.org/10.1111/j.1467-9221.2008.00668.x

Cralley, E. L., \& Ruscher, J. B. (2005). Lady, girl, female, or woman: Sexism and cognitive busyness predict use of gender-biased nouns. Journal of Language and Social Psychology 24(3), 300-314. https://doi.org/10.1177/0261927X05278391 


\section{KATIE SLEMP}

de Onís, M. C. (2017). What is an "x"? An exchange about the politics of "Latinx." Chiricú Journal: Latinalo Literatures, Arts, and Cultures 1(2), 78-91. https://www.muse.jhu.edu/article/664597

DeGuzmán, M. (2017). Latinx: ¡Estamos aquí!, or being "Latinx” at UNC-Chapel Hill. Cultural Dynamics 29(3), 214-230. https://doi.org/10.1177/0921374017727852

Eckert, P. \& McConnell-Ginet, S. (2003). Language and gender. Cambridge University Press. https://doi.org/10.1017/CBO9780511791147

Ehrlich, S. \& King, R. (1992). Gender-based language reform and the social construction of meaning. $\quad$ Discourse \& $\quad$ Society 3(2): 151-166. https://doi.org/10.1177/0957926592003002002

Fishbein, M. \& Ajzen, I. (2010). Predicting and changing behavior: The reasoned action approach. Psychology Press. https://doi.org/10.4324/9780203838020

Fought, C. (2013). Ethnicity. In J.K. Chambers \& N. Schilling (Eds.), The handbook of language variation and change, $16 \mathrm{j}-1 \mathrm{~h} . \quad 2 \mathrm{nd}$ ed. John Wiley \& Sons, Inc. https://doi.org/10.1002/9781118335598

Guidotti-Hernández, N. (2017). Affective communities and millennial desires: Latinx, or why my computer won't recognize Latina/o. Cultural Dynamics 29(3), 141-159. https://doi.org/10.1177/0921374017727853

Haddock-Lazala, C. M. (2016). Life and breasts at the borderlands: The breast reconstruction decision-making experiences of Dominican and Puerto Rican Latinxs. (Publication No. 10163151) [Doctoral dissertation, New School University]. ProQuest Dissertations Publishing.

Jacobson, M. B. \& Insko, W. R. (1985). Use of nonsexist pronouns as a function of one's feminist orientation. Sex Roles: A Journal of Research 13(1-2), 1-7. https://doi.org/10.1007/BF00287456

Jost, J. T., and Kay, A. C. (2005). Exposure to benevolent sexism and complementary gender stereotypes: Consequences for specific and diffuse forms of system justification. Journal of Personality and Social Psychology 88(3), 498-509. https://doi.org/10.1037/0022$\underline{3514.88 .3 .498}$

Kirkham, S. \& Moore, E. (2013). Adolescence. The handbook of language variation and change, 399p-3100j. 2nd ed. John Wiley \& Sons, Inc. https://doi.org/10.1002/9781118335598

Loporcaro, M. (2018). Grammatical gender in Romance. Gender from Latin to Romance. Oxford University Press, 33-61. https://doi.org/10.1093/oso/9780199656547.001.0001

Milian, C. (2017). Extremely Latin, XOXO: Notes on Latinx. Cultural Dynamics 29(3),121-140. https://doi.org/10.1177/0921374017727850

Ministerio de Educación y Ciencia. (1988). Recomendaciones para el uso no sexista de la lengua. Ministerio de Educación y Ciencia.

Padilla, Y. (2016). What does "Latinx" mean? A look at the term that's challenging gender norms. Complex. Retrieved from http://www.complex.com/life/2016/04/latinx.

Patterson, H. (2017). A sociolinguistic survey of "Latinx." (Publication No. 14) [Honors thesis, University of North Georgia]. https://digitalcommons.northgeorgia.edu/honors theses/14

Pauwels, A. (2008). Linguistic sexism and feminist linguistic activism. In J. Holmes and M. Meyerhoff (Eds.), The handbook of language and gender. John Wiley \& Sons, Inc. https://doi.org/10.1002/9780470756942 


\section{ATTITUDES TOWARDS VARIED INCLUSIVE LANGUAGE USE IN SPANISH}

Prewitt-Freilino, J., Caswell, A., \& Laakso, E. (2012). The gendering of language: A comparison of gender equality in countries with gendered, natural gender, and genderless languages. Sex Roles 66(4), 268-281. https://doi.org/10.1007/s11199-011-0083-5

Queen, Robin. (2013). Gender, sex, sexuality, and sexual identities. In J.K. Chambers \& N. Schilling (Eds.), The handbook of language variation and change, 13-16i. 2nd ed. John Wiley \& Sons, Inc. https://doi.org/10.1002/9781118335598

R Core Team. (2018). R: A language and environment for statistical computing. [Computer software]. Retrieved from https://cran.r-project.org/.

Ramírez Vélez, J. M. (2009). 10 recomendaciones para el uso no sexista del lenguaje. Conapred.

Real Academia Española. (2018). Libro de estilo de la lengua española según la norma panhispánica. Espasa.

Rubin, D., Greene, K., \& Schneider, D. (1994). Adopting gender-inclusive language reforms. Journal of Language and Social Psychology 13(2), 91-114. https://doi.org/10.1177/0261927X94132001

Salinas, C. \& Lozano, A. (2019). Mapping and recontextualizing the evolution of the term Latinx: An environmental scanning in higher education. Journal of Latinos and Education 18(4), 302-315. https://doi.org/10.1080/15348431.2017.1390464

Sarlo, B. \& Kalinowski, S. (2019). La lengua en disputa: Un debate sobre el lenguaje inclusivo. Ediciones Godot.

Sarrasin, O., Gabriel, U., \& Gygax, P. (2012). Sexism and attitudes toward gender-neutral language: The case of English, French, and German. Swiss Journal of Psychology 71(3), 113-124. https://doi.org/10.1024/1421-0185/a000078

Scharrón-Del Río, M. R. \& Aja, A. A. (2020). Latinx: Inclusive language as liberation praxis. Journal of Latinx Psychology 8(1), 7-20. https://doi.org/10.1037/lat0000140

Sczesny, S., Formanowicz, M., \& Moser, F. (2016). Can gender-fair language reduce gender stereotyping and discrimination? Frontiers in Psychology 7(25). https://doi.org/10.3389/fpsyg.2016.00025

Sczesny, S., Moser, F., \& Wood, W. (2015). Beyond sexist beliefs: How do people decide to use gender-inclusive language? Personality and Social Psychology Bulletin 41(7), 943-954. https://doi.org/10.1177/0146167215585727

Slemp, K. (2020). Latino, Latina, Latin@, Latine, and Latinx: Gender Inclusive Oral Expression in Spanish. Electronic Thesis and Dissertation Repository. 7297. https://ir.lib.uwo.ca/etd/7297

Slemp, K., Díaz, Y., \& Heap, D. (2019). Todxs lxs youtuberxs: pronunciaciones del lenguaje inclusivo por hispanohablantes en línea. Paper presented at the annual meeting of the Canadian Association of Hispanists, Vancouver, BC.

Stout, J. G., \& Dasgupta, N. (2011). When he doesn't mean you: Gender-exclusive language as ostracism. Personality and Social Psychology Bulletin 37(6), 757-769. https://doi.org/10.1177/0146167211406434

Swim, J., Mallett, R., \& Stangor, C. (2004). Understanding subtle sexism: Detection and use of $\begin{array}{lllll}\text { sexist language. } & \text { Sex }\end{array}$ https://doi.org/10.1023/B:SERS.0000037757.73192.06

The jamovi project (2019). jamovi. (Version 1.1) [Computer Software]. Retrieved from https://www.jamovi.org.

Vidal-Ortíz, S. \& Martínez, J. (2018). Latinx thoughts: Latinidad with an X. Latino Studies 16(3), 384-395. https://doi.org/10.1057/s41276-018-0137-8 


\section{KATIE SLEMP}

Zentella, A.C. (2017). "Limpia, fija y da esplendor": Challenging the symbolic violence of the Royal Spanish Academy. Chiricú Journal: Latina/o Literatures, Arts, and Cultures 1(2), 21-42. https://doi.org/10.2979/chiricu.1.2.04 